\title{
Human resources relations: A new paradigm for better theorizing and research on the HR/IR field
}

Downloads: The fulltext of this document has been downloaded 187 times since 2009

DOI (Permanent URL): 10.1108/S0742-6186(2009)0000016009

Citation:Kenneth F. Walker (2009), Human resources relations: A new paradigm for better theorizing and research on the HR/IR field, in David Lewin, Bruce E. Kaufman (ed.) 16 (Advances in Industrial \& Labor Relations, Volume 16), Emerald Group Publishing Limited, pp.137-159

\section{The Authors}

Kenneth F. Walker,

\begin{abstract}
This new, dynamic, value-free universal paradigm supplies new concepts for the explanation of all HR/IR phenomena as products of the interaction of impersonal environmental forces with the direct and indirect stakeholders' relevant characteristics, preferences, and expedients. It supplies new concepts for the inputs of the employee and the employer into their two-way employment interaction that brings about the productive and nonproductive utilization of the employee's human resources in an employment relationship. New concepts are also proposed for stakeholders' decisions on action to defend and/or advance their preferences and/or expedients. The paradigm recognizes that such action always takes place in formal/informal influence channels leading to formal/informal decision arenas. It analyzes the possible outcomes of the interacting forces. The feedback of such outcomes to the stakeholders and their environments thus produces a continuous flow of HR/IR phenomena that remains constant unless the strength and/or composition of the forces change. Diagrams illustrate these new concepts and a practical example showing how their use improves research and theory.
\end{abstract}

\section{Book series:}

Advances in Industrial \& Labor Relations

\section{Book Volume:}

16

Year:

2009

pp:

137-159

\section{Copyright $\mathbb{C}$}

Emerald Group Publishing Limited

This article is (c) Emerald Group Publishing and permission has been granted for this version to appear here (http://research-repository.uwa.edu.au/). Emerald does not grant permission for this article to be further copied/distributed or hosted elsewhere without the express permission from Emerald Group Publishing Limited. 


\section{ISSN:}

0742-6186

\section{ISBN:}

978-1-84855-396-5

\section{General characteristics of human resources relations paradigm}

\section{Interacting Forces}

The new paradigm presented here is called human resources relations (HRR) because it is based on the observation that HR/IR phenomena are always the product of interacting relations between a number of forces.

Some of these forces are impersonal environmental forces; others are behavioral, consisting of the stakeholders' actions that are intended to influence HR/IR phenomena. The environmental forces have interacting relations (for example, economic forces have interacting relations with political forces). The behavioral forces also have interacting relations with one another (for example, stakeholders often try to influence one another's behavior). Also, the two groups of forces have interacting relations. For example, stakeholders respond to environmental forces and may try to influence the environment (for example, governments may try to influence the economy).

\section{Improvements to Theorizing and Research}

The HRR paradigm improves theorizing and research on HR/IR phenomena in three ways:

1)It shows that it is possible to develop a single conceptual approach to the study of the whole range of highly diverse phenomena in the HR/IR field, wherever and whenever these occur (or have occurred) and whatever their nature (thus integrating the HR and IR theoretical approaches).

2)Being comprehensive, it ensures that none of the relevant forces is overlooked.

3)It supplies a comprehensive practical guide to the formulation of hypotheses and their testing, and to generalizations from such research.

All other current conceptual frameworks are inadequate in one or more ways. For example, some apply to only one country or one group of countries. Some apply only to HR/IR phenomena within the work organization or outside the work organization. Some are concerned only with a single dimension of HR/IR phenomena, such as legal aspects or political aspects. Some are based on an ideology, such as Marxism or free-market capitalism. Some are based on ethical judgments of HR/IR phenomena that occur (or have occurred) and/or the extent to which these phenomena serve certain goals, such as productive efficiency, industrial peace, industrial democracy, or "fairness" to all or certain groups of stakeholders. The HRR paradigm is free of all such weaknesses.

The HRR paradigm accommodates and integrates the insights and discoveries of all the various disciplines that study some aspect of the HR/IR field in "relatively fragmented and disconnected fashion" (Kaufman, 2004, p. 63). By integrating our present state of knowledge into a coherent whole, the HRR paradigm makes further research and theorizing additive.

This article is (c) Emerald Group Publishing and permission has been granted for this version to appear here (http://research-repository.uwa.edu.au/). Emerald does not grant permission for this article to be further copied/distributed or hosted elsewhere without the express permission from Emerald Group Publishing Limited. 


\section{New Concepts Based on Observation of HR/IR Phenomena}

The HRR paradigm achieves these improvements by introducing a number of new concepts that conceptualize aspects of HR/IR phenomena that have previously been inadequately conceptualized, or not conceptualized at all. These new concepts are illustrated and explained in the figures and tables in this paper.

These new concepts are empirically based, resting on the following observations of HR/IR phenomena:

1)The purpose and function of all employment relationships everywhere are that a would-be employer shall rent and utilize a would-be employee's human resources, under agreed conditions, for agreed purposes.

2)The utilization of human resources in an employment relationship can only be performed by the employment behavior of the employee in an employment context provided by the employer (employment behavior is the product of the two-way interaction between two inputs: the employee's deployment of his/her human resources and the employment context provided by the employer; the employee's human resources have two dimensions: the employee's performance capacities and his/her readiness to deploy these in the given employment context; an employment context has three dimensions: technological, administrative, and human; employment behavior consists of all of the employee's productive and unproductive behavior in the employer's time).

3)A number of individuals, groups, and organizations in addition to the employer and employee are stakeholders to the existence and number of employment relationships, to the nature of the utilization of human resources within such relationships, and to the conditions under which it occurs (the HR/IR phenomena to which they are stakeholders will be referred to for short here as HRUE (human resources utilization in employment)).

4)Both direct stakeholders (the employer and the employee) and indirect stakeholders have HRUE preferences and expedients, their preferences being the HRUE situation they would choose, given a free choice, and their expedients being HRUE situations they are willing to accept if necessary.

5)Stakeholders try to defend and/or advance their preferences and expedients by activities that are intended to influence HRUE and decisions that could affect it; such activities will be termed HRUE action.

6)HRUE action takes place in formal and informal influence channels that lead to formal and informal decision arenas where decisions that could affect HRUE are made (both influence channels and decision arenas may be within or outside the work organization - a parliament that passes labor laws is an example of an external decision arena; lobbying the parliament is an external influence channel; asking for a raise uses an internal influence channel leading to the internal decision arena where such decisions are made).

7)Stakeholders are presented with HRUE pressures and opportunities by a number of interacting impersonal environmental HRUE forces (an HRUE force is any force that could influence HRUE).

This article is (c) Emerald Group Publishing and permission has been granted for this version to appear here (http://research-repository.uwa.edu.au/). Emerald does not grant permission for this article to be further copied/distributed or hosted elsewhere without the express permission from Emerald Group Publishing Limited. 
8)HR/IR phenomena in a given situation constitute a system of constantly interacting HRUE forces (this interaction produces outcomes consisting of resultants and effects; resultants consist of HRUE or its cessation; effects consist of simultaneous positive, neutral, or negative production effects and preference effects).

\section{Levels of Abstraction}

Because the HRR paradigm is universal, applicable to all HR/IR phenomena, wherever and whenever they occur (or have occurred), and whatever their nature, its universal form must be highly abstract. Otherwise, it would not apply to the whole range of diverse HR/IR phenomena. The abstract universal version of the HRR paradigm is displayed in Fig. 1.

When applied to certain categories of HR/IR phenomena, such as those within the work organization or those outside the work organization, a less abstract form of the HRR paradigm is appropriate. The versions of the HRR paradigm that apply to HR/IR phenomena inside or outside the work organization are nevertheless abstract because in reality these two kinds of HR/IR phenomena are always present and interacting with each other, as illustrated in Fig. 2.

When applied to specific concrete HR/IR situations (for example, a particular industry, company, workshop, or office), the paradigm takes concrete form. These various levels of abstraction are illustrated in the figures that follow, with accompanying explanations.

Being universal, the HRR paradigm is also comprehensive. It is not limited to a single country or group of countries. It is not limited to HR/IR phenomena in certain locations within a country, such as within or outside the work organization, specific industries, companies, departments, or workplaces. It is not limited to a single disciplinary point of view, such as legal, economic, or political. It includes the whole range of HRUE action.

HRUE action varies very widely on a number of dimensions, such as target, duration, importance to the economy or community, spontaneous/planned, legal/illegal, cooperative/conflictual, peaceful/violent, cultural, and so on. Employees' productive employment behavior and the employer's employment context are forms of HRUE action, since they are intended to influence HRUE. The influence channels and decision arenas relevant to specific HRUE actions vary widely in formality and on other dimensions.

An example of cultural variation in HRUE action is "gherao," the technique practiced by employees in parts of India to express their disapproval of their employer's actions. They surround the employer in a circle of hostile stares, in an effort to shame him into changing his conduct. This technique is unique to India.

There is no shortage of examples of illegal HRUE action, as shown by the recent scandals at Siemens and Volkswagen in Germany over corruption and bribery directed at fostering unionmanagement relationships more favorable to the companies than the present ones (International Herald Tribune, 2007).

\section{HRR universal paradigm}

In Fig. 1, which portrays the universal form of the HRR paradigm, the extreme left-hand panels show pressures and opportunities from impersonal environmental forces interacting with direct and indirect stakeholders who have certain HRUE characteristics that influence their HRUE action. The various types of impersonal environmental forces are listed in Table 1. This table has been constructed as though it were to be applied to a whole country. When applied to smaller

This article is () Emerald Group Publishing and permission has been granted for this version to appear here (http://research-repository.uwa.edu.au/). Emerald does not grant permission for this article to be further copied/distributed or hosted elsewhere without the express permission from Emerald Group Publishing Limited. 
HR/IR units, appropriate adjustments need to be made. For example, in a specific department or office of a company, the environmental HRUE force, "population," would be adjusted to "how many people are there in this unit?" and "what are their relevant characteristics?" "Trends and cycles of economy" would be adjusted to "relevant economic trends and cycles."

Table 2 lists a number of types of stakeholder characteristics that may influence stakeholders' HRUE action. These characteristics may interact with one another. For example, a male employee aged 64 who will be eligible for a substantial pension on retirement is likely to produce different HRUE action from that of another 64-year-old male employee who is not eligible for a pension. Eligibility for a pension is an example of the type of characteristic labeled "resources" in Table 2. The comparison of the two 64-year-olds illustrates demographic characteristics interacting with stakeholders' resources.

The product of the interaction between environmental pressures and opportunities is the stakeholders' situational assessments, as shown in the next panel to the right in Fig. 1. Stakeholders base their decisions about whether to change their HRUE action, and if so, in what ways, on their situational assessments, which differ widely among stakeholders. Their situational assessments may be comprehensively informed, logically calculated, and short term or long term, in varying degree. Memories of past experiences and/or forecasts of the future may play a role.

Stakeholders' situational assessments include the available influence channels and decision arenas, and the possibility of creating new ones (for example, establishing a union). They also include their judgments of the pressures and opportunities that environmental forces present to themselves and other relevant stakeholders. Judgments are also made of the likely situational assessments of other relevant stakeholders and their subsequent HRUE action.

The next panel to the right in Fig. 1 shows the stakeholders' interacting HRUE actions, which may occur within or outside the work organization. Inside the work organization, work performed by employees and the employer's input into HRUE in the form of an employment context (for example, provision of the workplace) are HRUE action. Also, employees may work harder or reduce their effort, or approach the government (probably through their union, if there is one) to try to persuade it to alter the labor laws. Employers may also alter their work rules within the work organization or approach the government or perhaps try to influence other employers through an employers' federation.

Outcomes of the system, both within the work organization and outside it, are shown on the right of Fig. 1. These outcomes are fed back to the stakeholders and to the environment, producing a continuous flow of HRUE phenomena. Like the pattern on a flowing river, which remains constant until the forces determining it change in composition or relative strength, the flow of HR/IR phenomena remains constant unless the forces driving it change in composition or relative strength.

Thus, the HRR universal paradigm is a dynamic input-output-feedback system, sometimes referred to as an "open system" (Shirom, 1994), contrasting with the static, nondynamic systems proposed by Dunlop (1958) and Kaufman (2004).

The HRR paradigm takes account of stakeholders' values and norms, among their other HRUE characteristics, but sets no moral or other standards for either HRUE action or the outcomes of the system. The paradigm is value free. Readers and researchers are free to apply their own value judgments to any part of the system.

This article is (C Emerald Group Publishing and permission has been granted for this version to appear here (http://research-repository.uwa.edu.au/). Emerald does not grant permission for this article to be further copied/distributed or hosted elsewhere without the express permission from Emerald Group Publishing Limited. 


\section{HRR paradigms for HR/IR phenomena outside and inside the work organization}

Figs. 3 and 4 apply the HRR paradigm to HR/IR phenomena outside and within the work organization, respectively. In reality, the external and internal HR/IR phenomena interact and influence each other, as shown schematically in Fig. 2. For example, in the U.S.A., the Wagner Act affected internal HR/IR phenomena, but also laid down rules for collective bargaining outside the work organization. The two sets of phenomena differ in important ways, however, making it necessary to show the relevant forces in different diagrams.

\section{HRR Paradigm for HR/IR Phenomena Outside the Work Organization}

Fig. 3 differs from Fig. 1 only in specifying that one possible outcome may be the initial bargain establishing the employment relationship. This bargain may be stated with varying degrees of detail, varying from a simple verbal agreement to a lengthy written contract. In any case, it functions as a script for the working of the relationship, which the parties undertake to observe. Such undertakings vary in specificity. Some are dishonest (for example, the common Japanese practice of not allowing employees to take all the agreed holidays). Conflicts are common when the script is vague.

An important feature of external HR/IR phenomena, however, is that the HRUE action is mostly performed by indirect stakeholders and that there are many more of these than has been recognized in the literature. Table 3 lists the most important indirect stakeholders. Some readers may be surprised by the length of this list, but it is empirically based. All the listed types of indirect stakeholders have at one time or another played significant roles in HR/IR phenomena.

Labor laws are an important environmental force, making legislatures, governments and government agencies important omnipresent indirect stakeholders. The Wagner Act is an example.

Other employees in the same work organization may be concerned over what they perceive as discrimination, or over the terms of employment of the new employee. For example, when some American companies introduced the practice of paying new employees wages lower than those paid to existing employees doing the same work, many existing employees saw that as a threat to their wages. Other employees may also be interested in the perceived fairness of promotions.

A work stoppage in any work organization may cause layoffs in its suppliers, if the inactive organization is a major customer of the suppliers. For example, a work stoppage in the Boeing plant in Wichita, Kansas, would have a serious effect on its many suppliers in that city.

A work organization's business and/or consumer customers may be seriously inconvenienced if it has a work stoppage. Business customers may have to reduce operations, perhaps causing layoffs. Consumer customers may support the employees in the work organization, for example, by obeying a picket's call for them to boycott a store, thus influencing the outcome of the dispute.

Stockholders may be concerned over the cost of a work stoppage, or the damage to the company's public reputation by certain HR/IR practices. In the 1970s, for example, the Church of England put pressure on certain multinational British companies, in which it was a major stockholder, to raise the wages they paid in developing countries.

Since it is the function of unions and employer associations to protect and advance their members' preferences and expedients, they keep an eye on the HR/IR phenomena that could affect their members.

This article is (c) Emerald Group Publishing and permission has been granted for this version to appear here (http://research-repository.uwa.edu.au/). Emerald does not grant permission for this article to be further copied/distributed or hosted elsewhere without the express permission from Emerald Group Publishing Limited. 
When a work stoppage occurs in a work organization located in an isolated company town, local businesses that extend credit to the striking or locked-out employees may have an effect on the dispute, by enabling the employees to survive the period when they have no income.

Various special-interest pressure groups take an interest in a work organization's HRUE practices. Such groups pursue various preferences, such as women employees' rights, minority rights, prevention of sexual harassment, treatment of employees or suppliers' employees in developing countries, and so on. Some groups are motivated by their religions, others by political concerns, and others by their membership of or sympathy with the groups whose preferences they are concerned with. College students sometimes organize as pressure groups of various orientations, and may be influential, especially if they have a nationwide base.

A recent example of the far-reaching influence of pressure groups is the actions of some American multinational companies that have been criticized by such groups for having suppliers in China, where the labor laws are rarely enforced. Such companies are distant indirect stakeholders to their Chinese suppliers. Some of these indirect stakeholders have engaged Chinese companies to try to persuade the Chinese suppliers to observe the labor laws. The Chinese companies employed by the American companies have had mixed success.

In some countries, voters have had a significant impact on HRUE practices at times. In Australia in the early days of compulsory arbitration of industrial disputes by government tribunals, state governments that jailed union leaders for leading illegal strikes were all turned out of office by voters at the next elections. When the conservative federal government proposed, in 1927, to abolish federal industrial arbitral tribunals, it lost the next election. In some countries, voters who favor or oppose labor influence the labor laws and government labor policies.

When there is an important work stoppage, it is reported by the media, and its slant on the dispute may have some effect on public opinion and the outcome of the dispute. Press reports of the 1913 Ludlow massacre apparently changed John D. Rockefeller's policy on HRUE from one of confrontation to a more cooperative policy, which he worked hard to persuade other employers to follow (Kaufman, 2004, pp. 87-88). The stakeholders may try to influence the media in their favor. In Australia in 1950 the federal government placed full-page advertisements in all the leading newspapers throughout the country in order to win public support for its efforts to end a coal-mining strike that was crippling the nation's economy. In addition, reports by "muck-raking" journalists at times have had significant influence.

In the history of HRUE practices, a few authors have written novels that had a significant influence on these practices in certain industries. Examples are Zola's Germinal about conditions in French coalmines and Upton Sinclair's The Jungle. In both these cases, remedial legislation soon followed their publication.

Occasionally, an influential individual tries to influence HRUE, and sometimes succeeds. In the early 1900s, a widespread work stoppage was paralyzing the Australian city of Melbourne. The parties were deadlocked because the employers refused to meet the union leaders. One day the newspapers announced that the chief justice of the state Supreme Court would donate five pounds (a considerable sum at the time) to the unions' strike fund every day until the employers agreed to meet and negotiate with the union leaders. The employers immediately did so, and the dispute was promptly settled. More recently, the mayor of Los Angeles appealed to the parties to settle a dispute between Hollywood writers and the studios that threatened to cause a work stoppage. He threatened no action by the city government, only calling for the parties to consider

This article is (c) Emerald Group Publishing and permission has been granted for this version to appear here (http://research-repository.uwa.edu.au/). Emerald does not grant permission for this article to be further copied/distributed or hosted elsewhere without the express permission from Emerald Group Publishing Limited. 
the effects of such a stoppage on the city community. His appeal had the desired effect. Another recent example is Barack Obama's public criticism of Walmart's wages policy. Walmart did raise its wages soon after Barack's criticism, although it did not refer to such criticism in its public announcements.

It is difficult to assess the impact of the writings and expert opinions and advice of HR/IR scholars and experts, but there have been instances of these influencing labor legislation and decisions of arbitrators. Examples include the Canadian Task Force studies and those of the British Royal Commission on Industrial Relations in the 1960s.

\section{HRR Paradigm for HR/IR Phenomena Within the Work Organization}

The far left-hand side of Fig. 4 differs from that of Fig. 3 in two ways. It shows direct stakeholders in place of the indirect stakeholders in Fig. 3 , and the environmental pressures and opportunities include the initial bargain.

The interaction of the environmental forces and the direct stakeholders' characteristics produces the stakeholders' situational assessments, which lead to their decisions on their HRUE action. Within the work organization, their HRUE actions consist of their inputs into interacting with each other in what is termed employment interaction (EI for short), which is continuous in working hours throughout the duration of the employment relationship.

The employee's input is termed employee engagement, which consists of two elements. These are performance attributes and readiness to deploy these attributes in EI. Performance attributes may be positive (for example, capacity to do the job) or negative (for example, carelessness or habitual lateness). Readiness may be high or low, perhaps even negative to certain tasks. When the employee deploys his/her performance attributes in the performance of the requirements of the job (that is, s/he "works"), the employee's behavior is HRUE action, because it is aimed at influencing HRUE.

The technological dimension of the employer's input into EI (the employment context) includes the physical workplace, the tasks to be performed, and the equipment to be operated. The administrative dimension includes works rules and operational procedures, the authority structure, wages and benefits, and so on. The human dimension is the way supervisors behave toward their staff. When a supervisor gives an order to the employee, or interacts with the employee in any other way intended to influence the employee's employment behavior, this is HRUE action, because it is aimed at influencing HRUE.

The employment context reflects the employer's strategic decisions that affect HRUE in the work organization. Such decisions may be made for reasons other than HRUE considerations, but may have repercussions on HRUE. For example, a company may decide to relocate in order to be nearer its main customers, which will have repercussions on its employees in the old location.

The HRR concept of EI is more satisfactory than the Marxist concept of the "labor process" (LP), because it includes both cooperative and conflictual interactions, and recognizes that most EI is a mixture of the two. Until recently, LP theorists have presented the LP as a one-sided activity of the employer that is necessarily conflictual (Thompson \& Newsome, 2004). They seem to have regarded the employee as an automaton that has to be coerced by the employer into working. Their concept has been an ideologically loaded Marxist concept without any adequate empirical research basis. Only very recently have LP theorists engaged in empirical research, only to find elements of cooperation as well as confrontation.

This article is (c) Emerald Group Publishing and permission has been granted for this version to appear here (http://research-repository.uwa.edu.au/). Emerald does not grant permission for this article to be further copied/distributed or hosted elsewhere without the express permission from Emerald Group Publishing Limited. 
Although EI is supposed to be governed by the script set by the initial bargain, departures from this script frequently occur, especially with vague initial bargains, most of which are unwritten. One or both parties may misunderstand or miscalculate the terms of the initial bargain, or they may interpret the practical implications of some terms of the script differently. For example, the script may say that the employee shall work a "reasonable" amount of overtime, but the parties may disagree over what amount is "reasonable." Another cause of departures from the script may be unforeseen circumstances, in which case the parties have to negotiate how these will be handled. Yet another cause is exploitation by one or both parties (termed "opportunism" in Williamson, 1985). For example, surveys reveal that about one-third of the resumes submitted with employment applications in the U.S.A. are false. Some sweatshop managers fail to pay the wages they promised. Unilateral departure from the script may lead to retaliatory departure by the other direct stakeholder.

The panel on the extreme right of Fig. 4 shows the outcomes of the HRUE forces at work, which are fed back to the stakeholders and the environment. The possible outcomes are shown in Fig. 5. Those labeled "resultants" consist of two possibilities: either HRUE proceeds or it does not. In either case, there will be effects on production and the preferences of the direct stakeholders and, possibly, of some indirect stakeholders. For example, a union may be concerned if the employee accepts terms of employment below the union rate, or other employers may be concerned if the employer provides a more attractive employment context than they do.

Production effects may be positive (contributing to higher production), neutral (no effect on production), or negative. Errors by the employee or a manager may merely waste time, not raising or reducing production, or they may have negative effects (like the Coors Brewery employee who was reported some years ago to have turned the wrong wheel and emptied the whole brew into the river).

Preference effects on both direct and indirect stakeholders may also be positive, neutral, or negative. Different stakeholders receive different preference effects. For example, an employer may be pleased by a positive production effect, but the employee may be worried that $\mathrm{s} / \mathrm{he}$ is working herself/himself out of the job.

\section{Applying the HRR paradigm to a concrete HR/IR situation}

To apply the HRR paradigm to a particular concrete HR/IR situation, we must determine the values in this situation of the variables identified above. To illustrate the procedure, the paradigm will be applied to a typical coalmine in New South Wales, Australia, in the period before World War II, after which the industry was mechanized, and HRUE practices radically changed. This industry has been chosen because a detailed study of HRUE phenomena in it is available (Walker, 1970, Chapter IX). The fact that this example concerns outdated HR/IR phenomena does not disqualify it as an appropriate example, because the HRR paradigm applies to HR/IR phenomena whenever and wherever they occur or have occurred. Peculiarities of the Australian environment do not disqualify these phenomena as an example because every concrete HRR situation must be located in a particular country, and the HRR conceptual paradigm is universally applicable.

Fig. 6 shows the pressures and opportunities presented to the direct stakeholders by the environment of a typical coalmine in the period in question. Fig. 7 shows the main HRUE characteristics of the direct stakeholders. It will be seen that both the environmental pressures

This article is (C Emerald Group Publishing and permission has been granted for this version to appear here (http://research-repository.uwa.edu.au/). Emerald does not grant permission for this article to be further copied/distributed or hosted elsewhere without the express permission from Emerald Group Publishing Limited. 
and opportunities and the direct stakeholders' HRUE characteristics are very different from those in other industries and locations (such as the other industries studied in Walker, 1970).

Fig. 8 shows the typical situational assessments of the direct stakeholders that are produced by the interaction of the environmental pressures and opportunities with the stakeholders' HRUE characteristics.

Fig. 9 shows the typical HRUE action of the direct stakeholders in response to their situational assessments, the outcomes of the interaction of their HRUE action, and the feedback of the resultants and effects to the stakeholders and the environment.

Figs. 6-9 in effect clothe the abstract variables shown in Figs. 1-5 with reality. They illustrate the practical application of the HRR paradigm in the real world. Although this example concerns an industry, rather than any other HR/IR unit (such as a country or a specific work organization or department of a work organization), the same procedures would be required for any other HR/IR unit.

\section{Using the HRR paradigm to develop hypotheses and theorize}

This process consists of three steps:

1) Identify salient features of one or more concrete HRUE situations and likely causal interactions.

2) Formulate hypotheses from step (1).

3) Confirm or disconfirm these hypotheses by empirical research and/or existing literature on empirical data.

Table 4 illustrates the first two steps in the case of the NSW coalmines described above. One hypothesis from Table 4 is that an isolated community of workers who work in the same kind of employment will develop strong solidarity in its HRUE action. Another such isolated community exists in New South Wales at Broken Hill, where almost all the males work in the metal mines. It displays very high solidarity, confirming the hypothesis. Another example from Table 4 is that a highly variable demand for labor will cause employees to try to control output (by quotas or other means). Such highly variable demand for labor occurred in the Queensland meatslaughtering industry during the same period and also on the Australian waterfront, thus confirming the hypothesis (Walker, 1970, Chapters VIII and X). Other examples could be given, but these will suffice to illustrate step (3).

\section{Theoretical perspectives generated by the HRR paradigm}

(1) HR and IR phenomena are conceptually identical, constituting a unitary field consisting of phenomena concerning the utilization of employees' human resources in an employment relationship, which has been studied from different points of view by various disciplines, the findings of which must be integrated by a universal conceptual framework.

This was first pointed out by Kaufman (1993, p. 169). The HRR paradigm conceptualizes the unity of the HR/IR field as a necessary foundation for all theorizing about it.

(2) A dynamic conceptual system is required that captures the dynamic character of all HR/IR phenomena, since these are the product of continuously interacting HRUE forces.

This article is (c) Emerald Group Publishing and permission has been granted for this version to appear here (http://research-repository.uwa.edu.au/). Emerald does not grant permission for this article to be further copied/distributed or hosted elsewhere without the express permission from Emerald Group Publishing Limited. 
(3) An adequate conceptual framework must apply to all kinds of HRUE action, whatever its nature and wherever and whenever they occur or have occurred.

Current research and theorizing often omit types of HRUE action such as violence and illegal action and also the role of indirect stakeholders in addition to the government, and consequently misinterpret some HRUE situations.

(4) The nature and role of influence channels and decision arenas must be specified.

As these shape stakeholders' HRUE action, such action cannot be understood unless this is done.

(5) An adequate paradigm must identify stakeholders' relevant HRUE characteristics and their interaction with environmental pressures and opportunities to produce their situational assessments.

A simple assumption that stakeholders' HRUE action is motivated by their economic interests is unrealistic, leading to misinterpretation of some HRUE situations. Differences in stakeholder' HRUE characteristics can be a critical factor in explaining differences in HRUE practices in different HRUE situations.

(6) HRUE can only be brought about by the employment behavior of the employee, which results from the two-way EI of the inputs of the employer and the employee. Such inputs may be cooperative or conflictual or both. Some employment behavior is nonproductive.

Some current theoretical perspectives assume that human resources can be utilized unilaterally by employers. LP theory is one example. Williamson's theorizing is another (Williamson, 1985), as he assumes that the labor law requirement that the employee obey reasonable orders of the employer is always carried out without employee protest or subversion. In fact, HRUE can only take place as a result of two-way interaction between the employer and the employee. Even highperformance work systems (HPWS) cannot be operated unilaterally by the employer.

(7) Theory and research should not be contaminated by the scholar's value judgments of desirable HRUE practices, actions, and outcomes.

Scholars are free to pose questions such as "Do these practices help to preserve capitalism?" or "Do these practices advance the HRUE preferences of employees?" Claims that HRUE "should" perform certain social functions do not help explain what happens. The HRR paradigm for theory and research makes no judgments on the merits of any HRUE practices and outcomes. It is concerned only with what happens.

\section{An appropriate name for the study of HR/IR phenomena}

When Kaufman claimed that HR/IR phenomena constitute a unified field of study, he stated that if an appropriate name could be found for the field, it would encourage scholars and students to recognize its unity (Kaufman, 1993, p. 176). "Human Resources Relations" appears to be such a suitable name. The term "Relations" implies that these phenomena involve interacting forces and multiple stakeholders' interactions, while "Human Resources" delineates this field of study from those that are not concerned with HRUE. It would also be an appropriate name for the kind of comprehensive and integrated introductory course envisaged by Kaufman.

\section{Figures}

This article is (c Emerald Group Publishing and permission has been granted for this version to appear here (http://research-repository.uwa.edu.au/). Emerald does not grant permission for this article to be further copied/distributed or hosted elsewhere without the express permission from Emerald Group Publishing Limited. 
Fig. 1 Universal Human Resources Relations Paradigm.

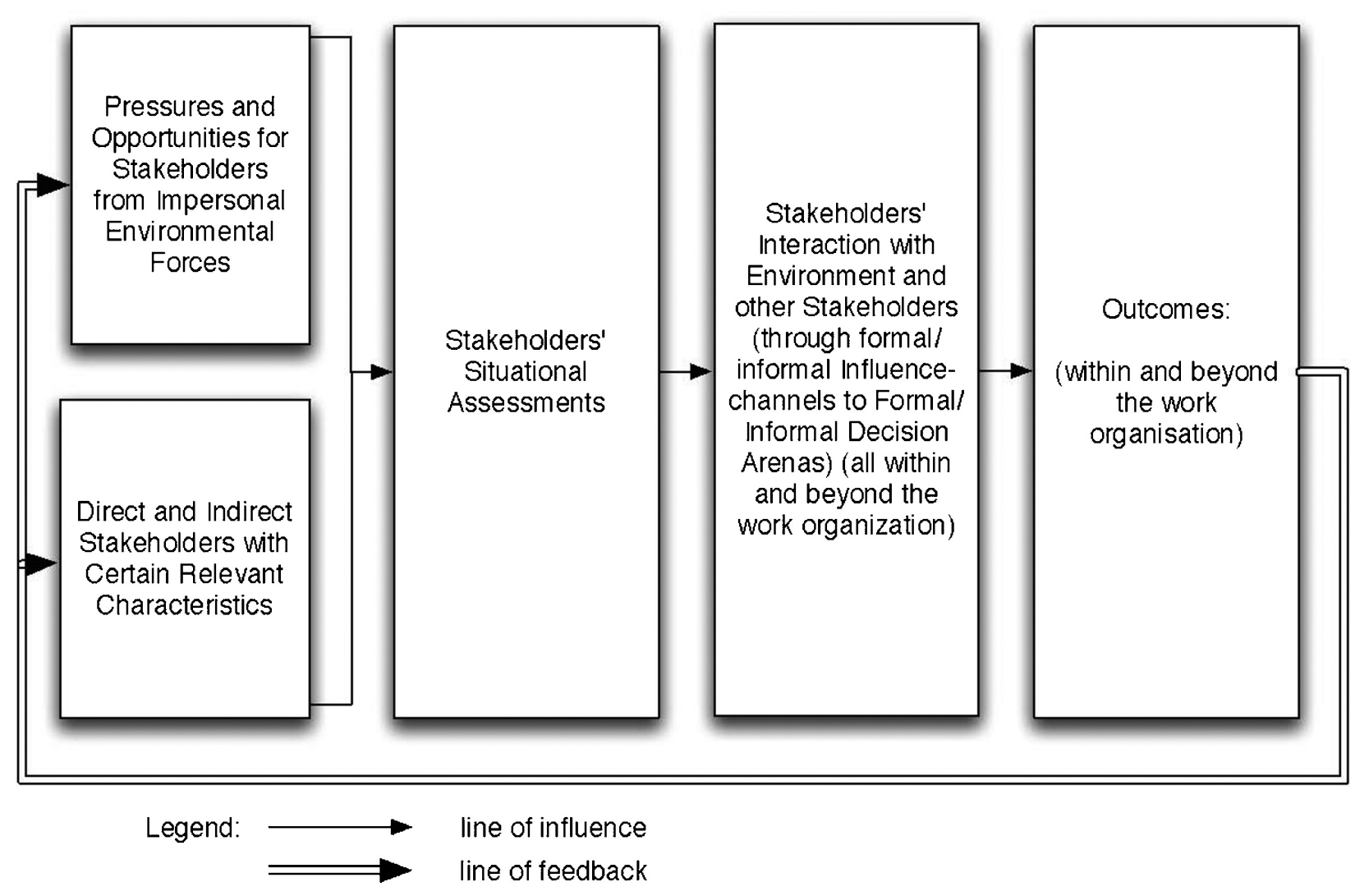

Fig. 2 Potential Interaction of HR/IR Phenomena Within and Outside the Work Organization.

This article is (c) Emerald Group Publishing and permission has been granted for this version to appear here (http://research-repository.uwa.edu.au/). Emerald does not grant permission for this article to be further copied/distributed or hosted elsewhere without the express permission from Emerald Group Publishing Limited. 


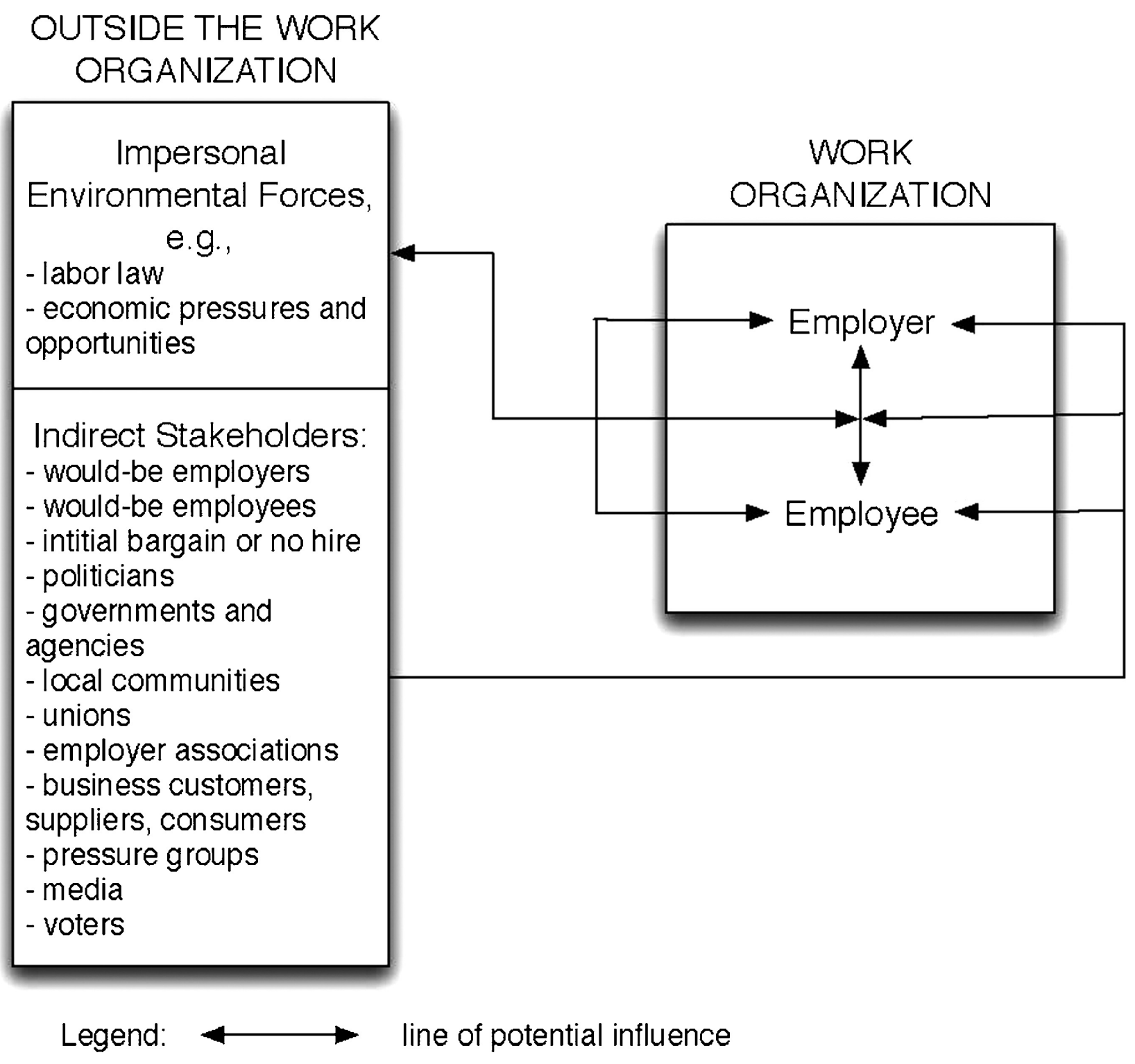

Fig. 3 HRR Paradigm for HR/IR Phenomena Outside the Work Organization.

This article is (c) Emerald Group Publishing and permission has been granted for this version to appear here (http://research-repository.uwa.edu.au/). Emerald does not grant permission for this article to be further copied/distributed or hosted elsewhere without the express permission from Emerald Group Publishing Limited. 


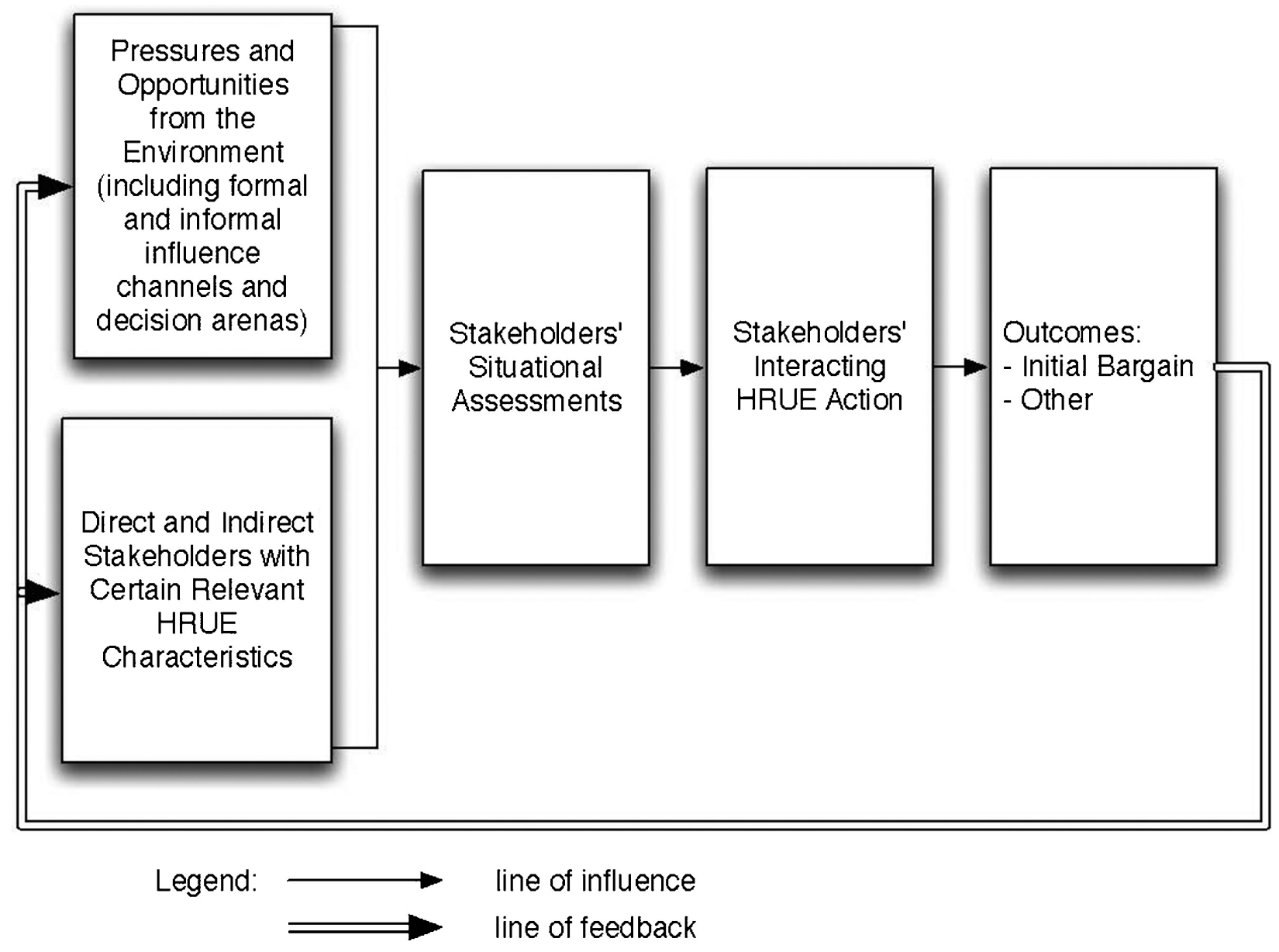

Fig. 4 HRR Paradigm for HR/IR Phenomena Within the Work Organization.

This article is () Emerald Group Publishing and permission has been granted for this version to appear here (http://research-repository.uwa.edu.au/). Emerald does not grant permission for this article to be further copied/distributed or hosted elsewhere without the express permission from Emerald Group Publishing Limited. 


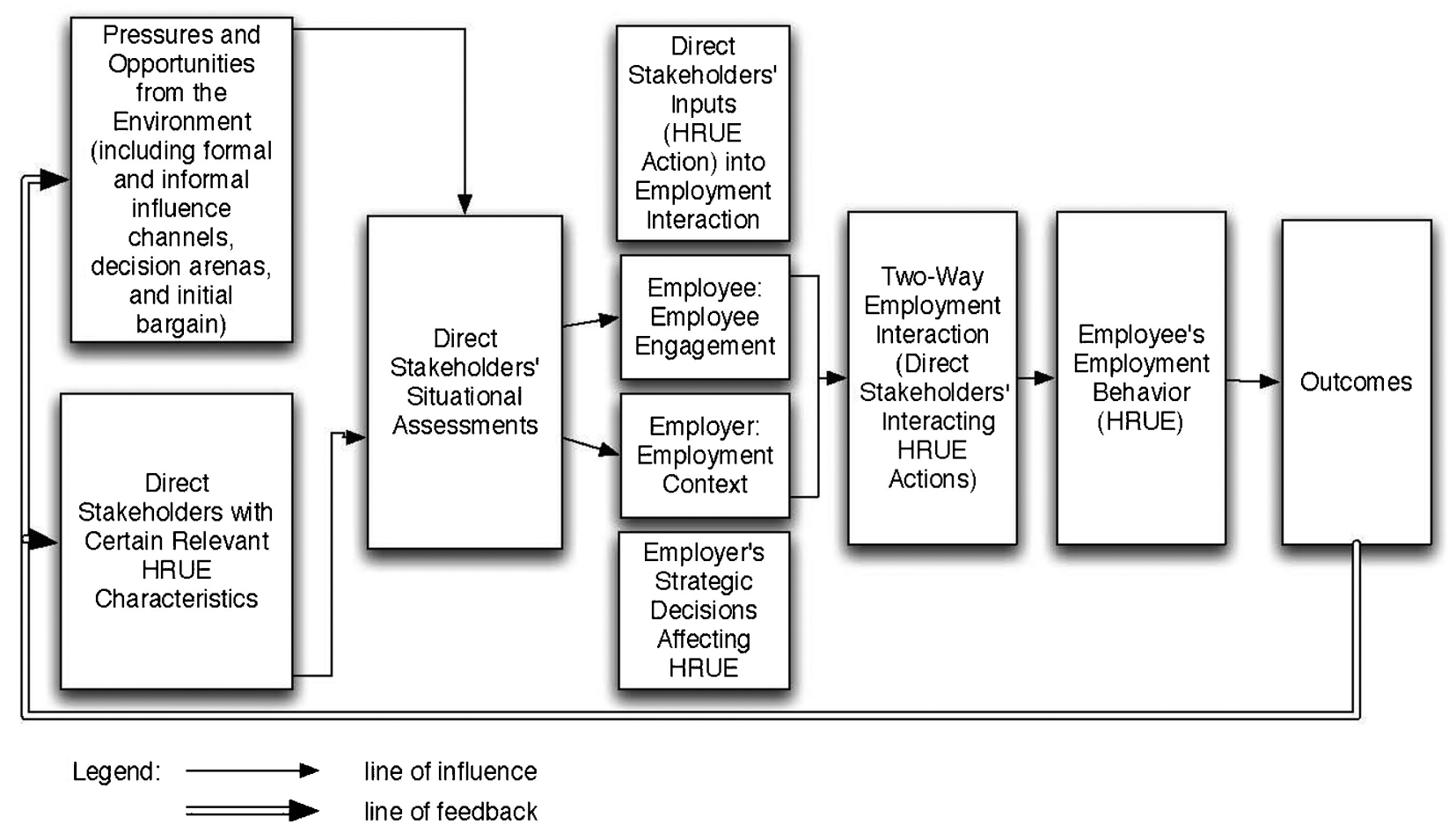

Fig. 5 Outcomes of Interacting HRUE Forces Within the Work Organization.

\section{O U T}

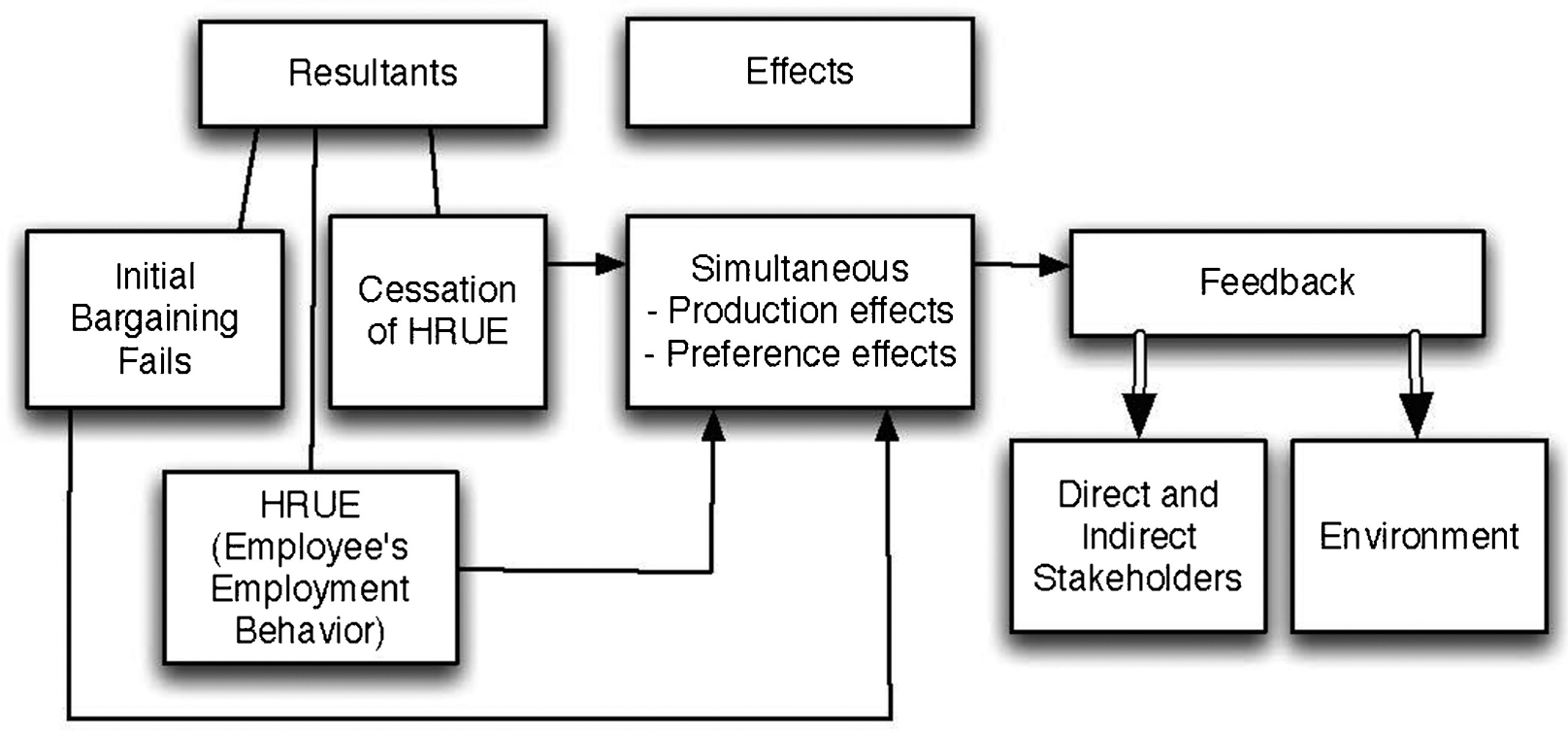

Legend: $\longrightarrow$ line showing different types of resultants

This article is () Emerald Group Publishing and permission has been granted for this version to appear here (http://research-repository.uwa.edu.au/). Emerald does not grant permission for this article to be further copied/distributed or hosted elsewhere without the express permission from Emerald Group Publishing Limited. 
Fig. 6 Environmental Pressures and Opportunities of Direct Stakeholders in NSW PreMechanized Coalmines.

Pressures from Environment

Coalminers:

- arduous, dangerous, risks

- unpredictable operational

contingencies

- very little alternative employment

- low demand for coal in depressions

- individual piece-work payment

- isolated small towns with poor

infrastructure and social amenities

- state mining and labor laws, with

compulsory arbitration of disputes

- fierce competition with other mines

- ruthless, intransigent employers with

solidarity in disputes

\section{Employers:}

- low demand for coal in depressions

- fierce competition with other mines

- no alternative labor supply

- state mining and labor laws, with compulsory arbitration of disputes

- suspicious labor force, with $100 \%$ solidarity determined to defend and advance wages, conditions, and rights
Opportunities in Environment

Coalminers:

- coal an essential commodity

- high demand for coal in

prosperity

- no alternative local labor supply

- very strong community support

- state mining and labor laws, with

compulsory arbitration of disputes

Employers:

- coal an essential commodity

- high demand for coal in prosperity

- export markets

- absence of alternative local employment

- state mining and labor laws, with

compulsory arbitration of disputes

- strong employer associations whose members constitute $95 \%$ of employers and who show high solidarity of employee relations policy

Fig. 7 HRUE Characteristics of Direct Stakeholders in NSW Pre-Mechanized Coalmines.

Coalminers' HRUE Characteristics

- male, militant, willing to break law by illegal strikes

$-17-18$ year-olds in strategic jobs

- most from several-generation coalmining

families

- suspicious, long, bitter tradition and

memories of confrontations

- $100 \%$ unionists, $100 \%$ solidarity, reinforced

by community pressure

- pro-labor politics, active radical political

parties (I.W.W., Communist)
Employers' HRUE Characteristics

- few large, many small companies

- many companies owned by large companies

outside mining industry

- tradition of confrontation to reduce labor costs

by illegal lockouts if necessary

- safety not a priority

- distant head offices directing mine managers

in disputes

- managers mostly not highly trained

- no concern for community welfare and

amenities

This article is () Emerald Group Publishing and permission has been granted for this version to appear here (http://research-repository.uwa.edu.au/). Emerald does not grant permission for this article to be further copied/distributed or hosted elsewhere without the express permission from Emerald Group Publishing Limited. 
Fig. 8 Typical Situational Assessment of Direct Stakeholders in NSW Pre-Mechanized Coalmines.

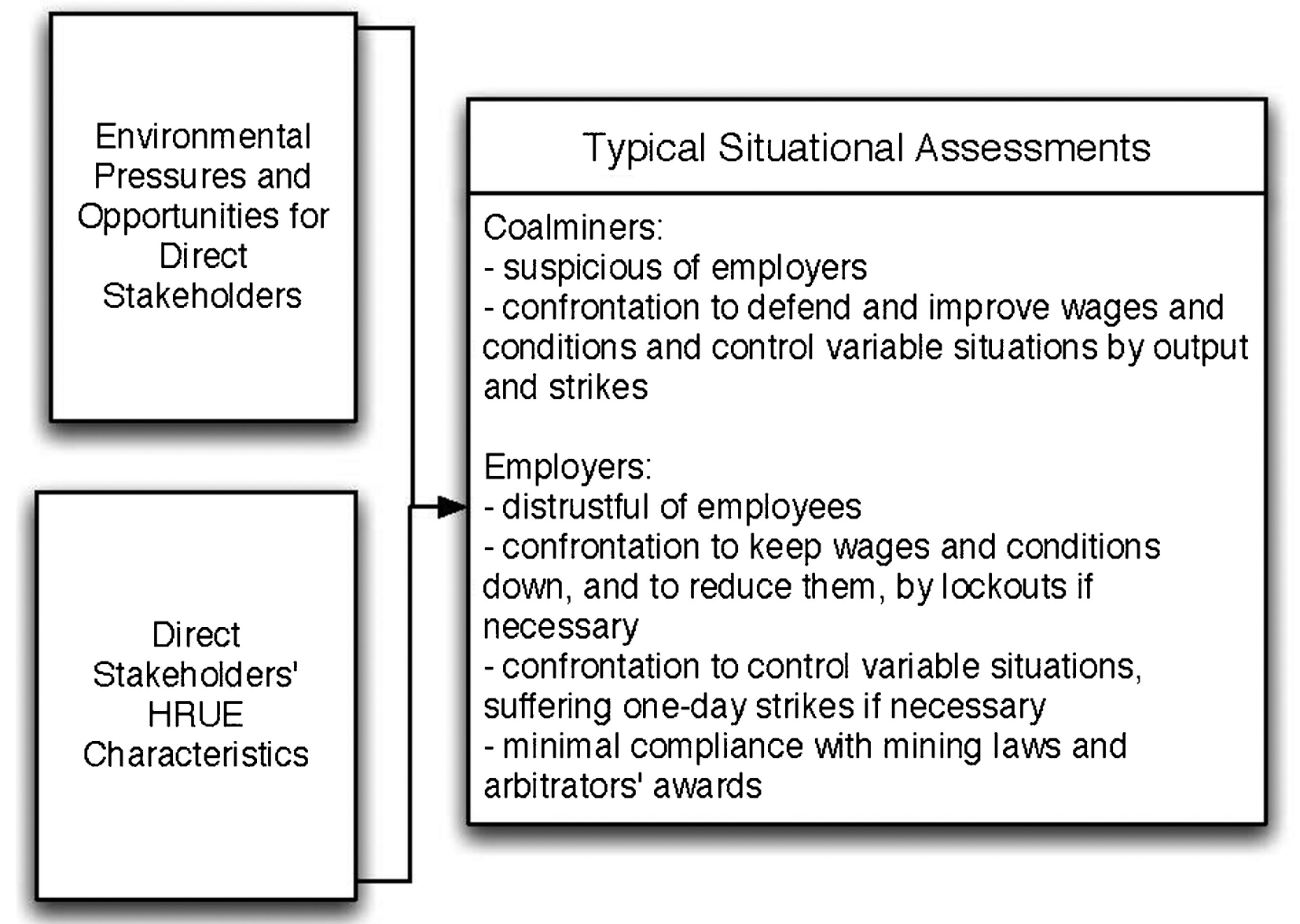

Fig. 9 Direct Stakeholders' HRUE Action, Outcomes and Feedback in NSW Pre-Mechanized Coalmines.

This article is () Emerald Group Publishing and permission has been granted for this version to appear here (http://research-repository.uwa.edu.au/). Emerald does not grant permission for this article to be further copied/distributed or hosted elsewhere without the express permission from Emerald Group Publishing Limited. 


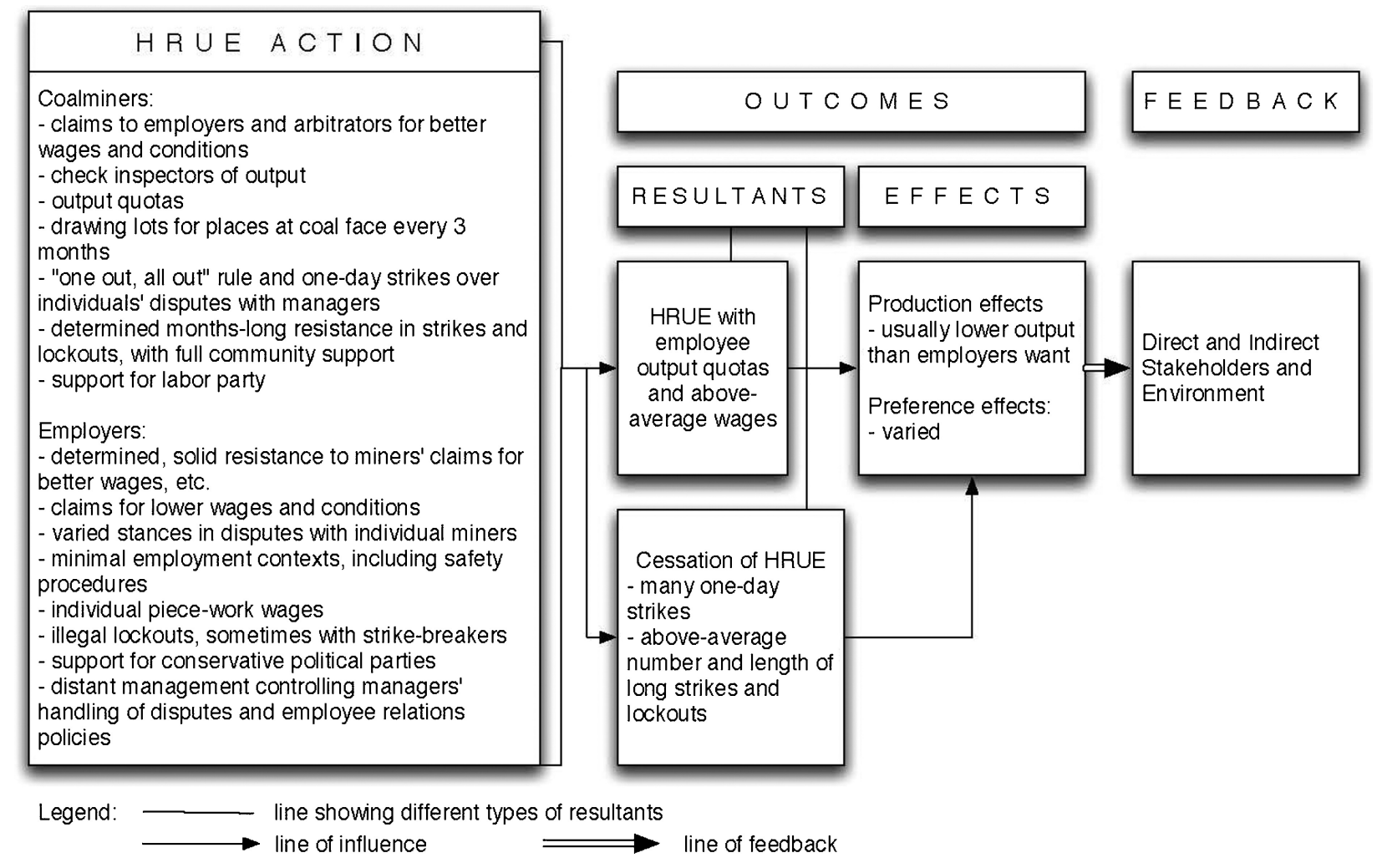

\section{Tables}

Table 1 Impersonal Environmental Forces Influencing HR/IR Phenomena

No image provided.

Table 2 Stakeholders' Characteristics Relevant to HRUE

No image provided.

\section{Table 3 Indirect Stakeholders to HR/IR Phenomena}

No image provided.

This article is () Emerald Group Publishing and permission has been granted for this version to appear here (http://research-repository.uwa.edu.au/). Emerald does not grant permission for this article to be further copied/distributed or hosted elsewhere without the express permission from Emerald Group Publishing Limited. 


\section{Table 4 Salient Features and Hypotheses: Pre-Mechanized NSW Coalmines}

No image provided.

\section{References}

J. Dunlop (1958), "Industrial relations systems", Southern University Press, Carbondale, IL, . [Manual request]

International Herald Tribune. (2007). International Herald Tribune, April 2.

B.E. Kaufman (1993), "The origins and evolution of the field of industrial relations in the United States", ILR Press, Ithaca, NY, .

[Manual request]

Kaufman B. E. (2004). Employment relations and the employment relations system: A guide to theorizing. In: B. E. Kaufman (Ed.), Theoretical perspectives on work and the employment relationship (pp. 63, 88). Champaign, IL: IRRA, Ch. 2.

A. Shirom (1994), "The system perspective in labor relations: Toward a new model", JAI Press, Greenwich, CN, pp.37 - 62.

[Manual request]

P. Thompson, K. Newsome (2004), "Labor process theory, work and the employment relation", in B.E. Kaufman (Eds),IRRA, Champaign, IL, pp.133 - 162.

[Manual request]

Walker K. F. (1970). Australian industrial relations systems. Cambridge, MA: Harvard University Press, Chs. VII-X.

O. Williamson (1985), "The economic institutions of capitalism", The Free Press, New York, . [Manual request]

This article is $\odot$ Emerald Group Publishing and permission has been granted for this version to appear here (http://research-repository.uwa.edu.au/). Emerald does not grant permission for this article to be further copied/distributed or hosted elsewhere without the express permission from Emerald Group Publishing Limited. 